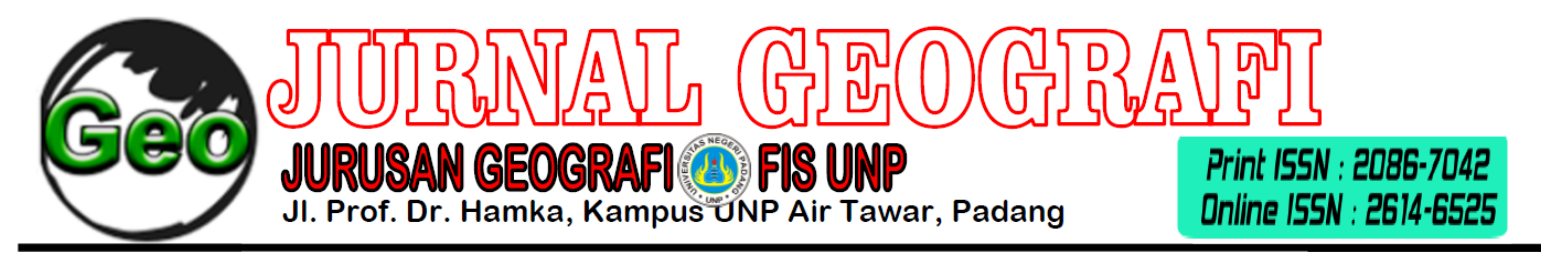

\title{
PERSEPSI DAN SIKAP MASYARAKAT TENTANG PERLINDUNGAN HUTAN DI NAGARI KAPAU ALAM PAUH DUO KECAMATAN PAUH DUO KABUPATEN SOLOK SELATAN
}

\author{
Rika Yulita, Iswandi U, Rahmanelli \\ ${ }^{1,2}$ Program Studi Pendidikan Geografi, \\ Fakultas Ilmu Sosial, Universitas Negeri Padang \\ Email: rikayulita39@gmail.com
}

\begin{abstract}
ABSTRAK
Penelitian ini bertujuan untuk mengetahui persepsi dan sikap masyarakat tentang perlindungan hutan di Nagari Kapau Alam Pauh Duo, Kecamatan Pauh Duo, Kabupaten Solok Selatan. Jenis penelitian ini adalah penelitian kualitatif. Data yang digunakan untuk melengkapi penelitian ini adalah data primer. Data primer diperoleh dari hasil wawancara langsung dengan masyarakat Nagari Kapau Alam Pauh Duo, Wali Nagari Kapau Alam Pauh Duo, Ketua Kerapatan Adat Nagari (KAN) Kapau Alam Pauh Duo. Teknik menentukan informan dengan cara purposive sampling. Teknik pengumpulan data dalam penelitian ini menggunakan teknik observasi, wawancara, dan dokumentasi. Teknik analisis data yaitu dengan cara reduksi data, penyajian data, dan penarikan kesimpulan. Hasil penelitian ini adalah: (1) persepsi masyarakat tentang perlindungan hutan dapat kita lihat bahwa masyarakat yang berpendidikan rendah ( Tidak tamat SD-SMA) dan bermata pencaharian sebagai petani berangggapan bahwa hutan itu sebagai mata pencaharian merekae dan sebagian masyarakat yang berpendidikan tinggi (PNS) menganggap bahwa hutan itu harus di jaga dan dilestarikan keberadaannya. (2) Sikap negatif masyarakat tentang perlindungan hutan dapat kita lihat bahwa masyarakat yang berpendidikan rendah ( Tidak tamat SD- SMA) dan bermata pencaharian sebagai petani, perabot kayu/toke kayu masih mengambil kayu-kayu besar yang ada di hutan dan sebagian masyarakat yang yang berpendidikan tinggi ( PNS) masih juga melakukan penyimpangan secara tidak langsung terhadap hutan.
\end{abstract}

Kata kunci : Perlindungan Hutan, Persepsi, Sikap

\begin{abstract}
This study aims to determine the perception and attitude of the community about forest protection in Nagari Kapau Alam Pauh Duo, Pauh Duo Subdistrict, South Solok Regency. This type of research is qualitative research. The data used to complete this research is primary data. Primary data was obtained from the results of direct interviews with the people of Nagari Kapau Alam Pauh Duo, Wali Nagari Kapau Alam Pauh Duo, Chair of Kerapatan Adat Nagari (KAN) Kapau Alam Pauh Duo. The technique of determining informants by purposive sampling. Data collection techniques in this study use observation, interview, and documentation techniques. Data analysis technique that is by way of data reduction, data presentation, and conclusion. The results of this study are: (1) community perception about forest protection can be seen that low educated people (Not finished primary-high school) and livelihood as a farmer assume that forest as their livelihood and some people with high education (PNS) considers that the forest should be guarded and preserved. (2)) Negative public attitudes about forest protection can be seen that low-educated people (not graduating from primary-high school) and livelihood as farmers, wooden furniture I toke woods are still taking large timber in the forest and some highly educated people (PNS) still indirectly deviate from the forest.
\end{abstract}

Keywords: Forest Protection, Perception, Attitude 


\section{Pendahuluan}

Hutan di Indonesia dianugerahkan Tuhan Yang Maha Esa dengan kekayaan alam berupa sumber daya alam yang melimpah. Sumber daya alam merupakan modal dasar pembangunan nasional di segala sektor, sebagai modal dasar pembangunan nasional sumber daya alam tersebut harus dimanfaatkan secara optimal bagi kesejahteraan rakyat Indonesia. Hutan perlu dijamin kesinambungan, keserasian, keselarasan dan keseimbangan baik antara manusia dengan pencipta Nya, manusia dengan manusia dan manusia dengan lingkungannya.

Kedudukannya sebagai salah satu penentu sistem penyangga kehidupan, hutan telah memberikan manfaat yang besar bagi umat manusia, oleh karena itu harus dijaga kelestariannya. Di tingkat nasional sudah ada yang mengatur tentang hutan, yaitu UU No. 41 Tahun 1999 Tentang Kehutanan. Hasil utama dari hutan produksi berupa kayu, sedangkan hasil lainnya disebut nirkayu yang mencakup rotan, bambu, tumbuhan obat, rumput, bunga, biji, kulit, daun, lateks (getah), resin (damar, kopal, gom, gondorukem, dan jernang), dan zat ekstraktif lainnya minyak (Indriyanto, 2010).

Menurut Supriyadi (2013) hutan adalah hamparan lahan atau tanah yang di dominasi pepohonan sebagai suatu ekosistem. Pengertian hutan tersebut sangat erat kaitannya dengan proses yang saling berhubungan sebagai berikut : Hidrologis, berarti bahwa hutan merupakan gudang penyimpanan air dan tempat menyerapnya air hujan maupun embun yang pada akhirnya akan mengalirkannya ke sungai-sungai yang memiliki mata air di tengah-tengah hutan secara teratur menurut irama alam. Hutan juga berperan penting untuk melindungi tanah dari erosi dan daur unsur haranya. Iklim, merupakan komponen ekosistem alam yang terdiri dari unsur-unsur hujan (air, sinar matahari dan suhu), angin dan kelembaban yang sangat mempengaruhi kehidupan yang ada di permukaan bumi, terutama iklim makro maupun mikro. Kesuburan tanah, berarti tanah merupakan pembentukan humus utama dan penyimpan unsur-unsur mineral bagi tumbuhan lain. Keanekaragaman genetik, berarti hutan memiliki kekayaan berbagai jenis flora dan fauna. Jika hutan tidak diperhatikan dalam pemanfaatan dan kelangsungannya, tidaklah mustahil akan terjadi erosi genetik. Hal ini di akibatkan oleh hutan semakin berkurang habitatnya. hutan juga memberikan fungsi kepada masyarakat sekitar hutan sebagai pemenuhan kebutuhan seharihari. Selain kayu dihasilkan bahan lain seperti damar, kopal, gondorukem, terpenting kayu putih, rotan dan tanaman obat-obatan.

Wilayah wisata alam, artinya hutan mampu berfungsi sebagai sumber inspirasi, nilai estetika, etika dan lainlain. Menurut Djaenudin 1994 dalam Nagel (2011), kawasan hutan perlu dipertahankan berdasarkan pertimbangan fisik, iklim dan pengaturan tata air serta kebutuhan sosial ekonomi masyarakat dan negara. Hutan yang dipertahankan terdiri dari hutan lindung, hutan suaka alam, hutan wisata, hutan konservasi, hutan produksi terbatas dan hutan produksi. 
Usaha, cara, dan metode pelestarian hutan dapat dilakukan dengan mencegah perladangan berpindah yang tidak menggunakan kaidah pelestarian hutan, waspada dan hati-hati terhadap api dan reboisasi lahan gundul serta tebang pilih tanam kembali (Organisasi KomIbutas dan Perpustakaan Online Indonesia, 2006 dalam Nagel, 2011).

Berikut teknik serta cara yang dapat digunakan untuk menjaga hutan kita tetap terjaga dari tangan-tangan perusak jahat. Perambahan hutan tanpa perencanaan dan etika untuk mencari keuntungan sebesarbesarnya sangatlah berbahaya karena dapat merusak alam dan juga habitat, komunitas hewan yang ada di dalamnya.

Cara pertama yaitu mencegah cara ladang berpindah. Terkadang para petani tidak mau pusing mengenai kesuburan tanah. Mereka akan mencari lahan pertanian baru ketika tanah yang ditanami sudah tidak subur lagi tanpa adanya tanggung jawab membiarkan ladang terbengkalai dan tandus. Sebaiknya lahan pertanian dibuat menetap dengan menggunakan pupuk untuk menyuburkan tanah yang sudah tidak produktif lagi.

Cara kedua, hindari membakar sampah, membuang puntung rokok, membuat api unggun, membakar semak, membuang obor, dan lain sebagainya yang dapat menyebabkan kebakaran hutan. Jika menyalakan api di dekat atau di dalam hutan dapat mengganggu kesehatan manusia dan hewan sekitar lokasi kebakaran dan juga tempat yang jauh sekalipun jika asap terbawa angin kencang.

Metode selanjutnya adalah reboisasi lahan gundul dan metode tebang pilih. Kombinasi kedua teknik adalah sesuatu yang wajib dilakukan para pelirik sertifikat hak pengelolaan hutan. Para perusahaan yang melakukan penebang pohon harus memilih-milih pohon mana yang sudah cukup umur dan ukuran untuk ditebang.

Selanjutnya yaitu menempatkan penjaga hutan / polisi kehutanan atau jagawana. Dengan menempatkan satuan pengaman hutan yang jujur, menggunakan teknologi dan persenjataan lengkap diharapkan mampu menekan maraknya aksi pengrusakan lingkungan yang ada.

Dalam Kamus Besar Bahasa Indonesia persepsi merupakan tanggapan (penerima) langsung dari suatu serapan atau proses seseorang mengetahui beberapa hal melalui panca inderanya. Sedangkan menurut Surwon, (1982) persepsi adalah kemampuan untuk membeda-bedakan, mengelompokkan, memfokuskan dan sebagainya itu disebut sebagia kemampuan untuk mengorganisasikan dan pengamatan. Selanjutnya menurut Gitosudarmo (2002) berpendapat persepsi adalah sebagai suatu proses memperhatikan dan menyeleksi, mengorganisasikan dan menafsirkan stimulus lingkungan. Setiap proses memperhatikan dan penyeleksi terjadi karena setiap panca indra diharapkan banyak stimulus lingkungan. Menurut Walgito (2003) hasil persepsi dapat di pengaruhi oleh dua faktor ,yaitu faktor internal dan eksternal; faktor internal adalah keadaan individu, baik yang berhubungan dengan jasmani maupun psikologis.; bila sistem fisiologis terganggu, hal tersebut akan mempengaruhi persepsi seseorang. Sedangkan psikologis terkait dengan 
pengalaman, perasaan, kemampuan berfikir ( pengetahuan), kerangka acuan, motivasi.

Sikap merupakan aspek penting yang dimiliki oleh seseorang menentukan tindakan pada suatu objek, sikap pada dasarnya dapat bereaksi pada orang, objek atau ide. Sikap tentang objek, gagasan atau orang tertentu merupakan orientasi yang bersifat menetap komponen kognitif, afektif dan prilaku, sedangkan komponen prilaku terdiri dari kesiapan seseorang untuk bereaksi pada objek. Sikap perwujudan perasaan seseorang serta penilaian terhadap pemahaman dan keyakinan maupun gagasan terhadap suatu untuk bertindak pada suatu objek. Istilah sikap jarang sekali didefenisikan sama oleh para ahli, pengertiannya dalam sikap selalu bervariasi antara satu dengan yang lainnya.

Menurut Thursione (1946) dalam Ahmadi (2007) menjelaskan bahwa sikap merupakan status mental seseorang yang terdiri dari afeksi untuk atau melawan (pendidikan), penilaian, suka atau tidak suka, tanggapan positif atau negatif terhadap suatu objek psikologis. Sikap yaitu kecenderungan yang relatif menetap untuk bereaksi dengan cara baik atau buruk terhadap orang atau barang tertentu, dengan demikian pada prinsipnya sikap dapat kita anggap sebagai suatu kecenderungan bertindak dengan tertentu terhadap suatu objek, tata nilai, peristiwa dan sebagainya. Slameto (2010) menjelaskan sikap dikatakan sebagai suatu respon. Respon akan timbul apa bila individu dihadapkan pada suatu stimulus atau rangsangan yang menghendaki timbulnya reaksi individual, respon evaluatif berarti bentuk respon yang dinyatakan sebagai sikap yang didasari oleh proses evaluasi dari diri individu. Hal ini dapat disimpulkan nilai stimulus dapat berbenntuk baik atau buruk, positif atau negatif, suka atau tidak suka, yang kemudian mengkristal sebagai reaksi terhadap objek sikap. Maksudnya bahwa sikap individu akan bersikap positif terhadap hal-hal yang akan mendatangkan manfaat dan bersikap negatif terhadap hal-hal yang membawa atau dapat merugikan bagi dirinya. Sikap yang positif ini akan mempengaruhi niat untuk ikut serta dalam kegiatan yang berkaitan dengan objek sikap.

Menurut Slameto, (2010) yang mempengaruhi sikap manusia yaitu:
a. Pengalaman pribadi seseorang
b. Pengaruh orang lain yang dianggap penting di dalam hidupnya
c. Media Massa
d. Alam

Kabupaten Solok Selatan mempunyai sumber daya alam yang melimpah, terutama sumber daya alam hutan. Kawasan hutan di Kabupaten Solok Selatan dapat kita lihat pada tabel di bawah ini :

\section{Tabel 1.}

Kawasan Hutan Kabupaten Solok Selatan Tahun 2011 (data terakhir diambil tahun 2011)

\begin{tabular}{llll}
\hline No & $\begin{array}{l}\text { Fungsi } \\
\text { Kawasan }\end{array}$ & $\begin{array}{l}\text { Luas } \\
(\mathrm{Ha})\end{array}$ & $\begin{array}{l}\text { Persentase } \\
(\%)\end{array}$ \\
& Hutan & & \\
\hline 1. & Kawasan & $65.732,4$ & 19,64 \\
& $\begin{array}{l}\text { Suaka Alam } \\
\text { (KSA) }\end{array}$ & & \\
\hline 2. & Hutan & $84.237,1$ & 25,17 \\
& Lindung & 3 & \\
\hline
\end{tabular}




\begin{tabular}{|c|c|c|c|}
\hline 3. & $\begin{array}{l}\text { Hutan } \\
\text { Produksi } \\
\text { Terbatas }\end{array}$ & $\begin{array}{l}53.616,2 \\
6\end{array}$ & 16,02 \\
\hline 4. & $\begin{array}{l}\text { Hutan } \\
\text { Produksi } \\
\text { Tetap }\end{array}$ & $\begin{array}{l}13.049,5 \\
0\end{array}$ & 3,90 \\
\hline 5. & $\begin{array}{l}\text { Hutan } \\
\text { Produksi } \\
\text { Konservasi }\end{array}$ & $\begin{array}{l}19.753,9 \\
6\end{array}$ & 5,90 \\
\hline 6. & $\begin{array}{l}\text { Areal } \\
\text { Penggunaan } \\
\text { Lain }\end{array}$ & $\begin{array}{l}98.230,7 \\
4\end{array}$ & 29,36 \\
\hline & & $\begin{array}{l}334.620, \\
00\end{array}$ & 100,00 \\
\hline
\end{tabular}

Sumber :Dinas Kehutanan dan

Perkebunan Kabupaten Solok Selatan

Salah satu Nagari yang ada di kabupaten Solok Selatan yang banyak terjadi penebangan kayu-kayu besar di hutan dan membuka lahan baru yaitu Nagari Kapau Alam Pauh Duo dengan luas hutan 1248,75 hektar.

Berdasarkan observasi yang peneliti lakukan di Nagari Kapau Alam Pauh Duo Kecamatan Pauh Duo Kabupaten Solok Selatan masyarakat disana telah menjadikan hutan bukan sebagai kawasan yang harus di lindunginya, tetapi telah menjadikan hutan tersebut sebagai kawasan yang harus di eksploitasi seperti membuka lahan baru untuk dijadikan areal perladangan, hal-hal seperti itulah yang menyebabkan terjadinya tekanan yang besar terhadap kelestarian hutan yang tidak mengindahkan lingkungan yaitu tanpa adanya kesadaran, keterampilan dalam penebangan pengelolaan hasil hutan, mereka selalu mementingkan kepentingan pribadi dan kelompok. Adapun tujuan penelitian ini adalah untuk memperoleh gambaran persepsi dan sikap masyarakat tentang perlindungan di Nagari Kapau Alam Pauh Duo Kecamatan Pauh Duo Kabupaten Solok Selatan.

\section{Metode Penelitian}

Jenis penelitian ini tergolong kepada penelitian kualitatif. Menurut Moleong (2006) penelitian kualitatif adalah penelitian yang bermaksud memahami fenomena apa yang dialami subjek penelitian

Data yang digunakan untuk melengkapi penelitian ini adalah data primer. Data primer diperoleh dari hasil wawancara langsung dengan masyarakat Nagari Kapau Alam Pauh Duo, Wali Nagari Kapau Alam Pauh Duo, Ketua Kerapatan Adat Nagari (KAN) Kapau Alam Pauh Duo. Teknik menentukan informan dengan cara purposive sampling. Teknik pengumpulan data dalam penelitian ini menggunakan teknik observasi, wawancara, dan dokumentasi. Teknik analisis data yaitu dengan cara reduksi data, penyajian data, dan penarikan kesimpulan.

\section{Hasil Penelitian Dan Pembahasan}

Berikut ini peta lokasi penelitian yang dilaksanakan di Nagari Kapau Alam Pauh Duo Kecamatan Pauh Duo Kabupaten Solok Selatan. 


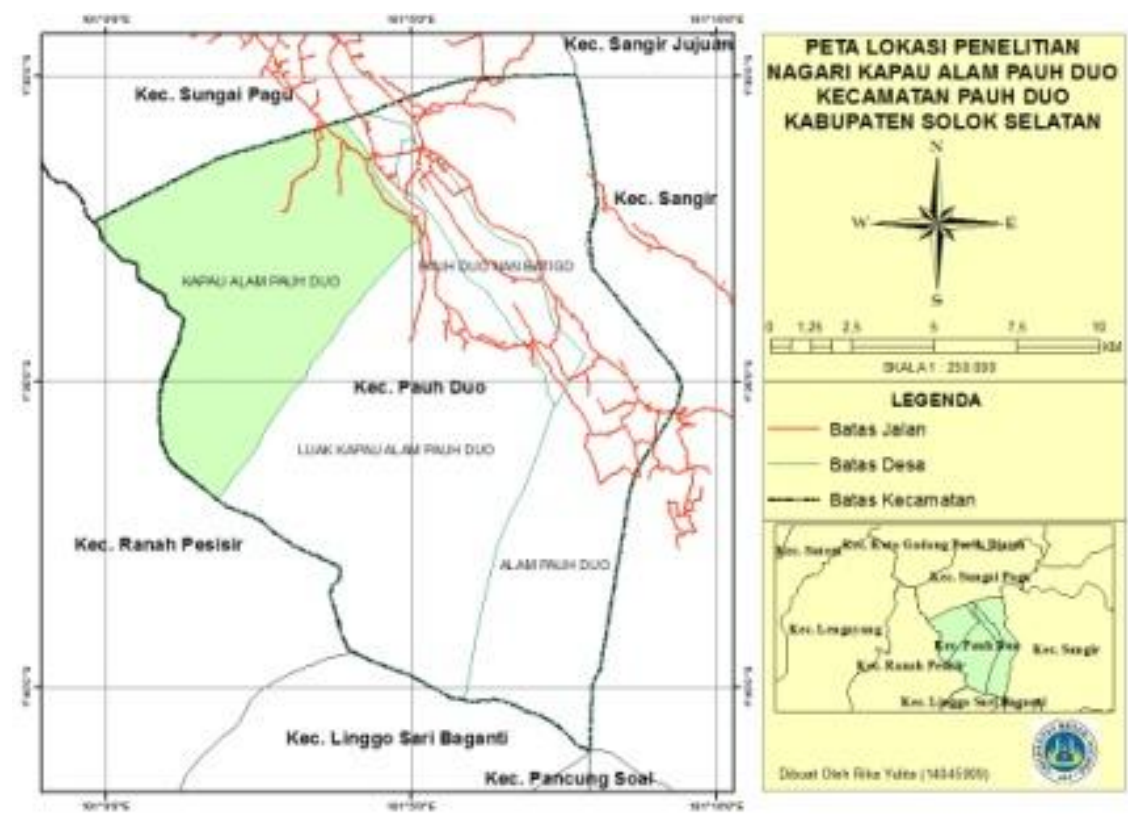

Gambar 1. Peta Lokasi Penelitian Nagari Kapau Alam Pauh Duo Kecamatan Pauh Duo Kabupaten Solok Selatan

Hasil penelitian ini akan memberikan gambaran persepsi dan sikap masyarakat tentang perlindungan hutan di Nagari Kapau Alam Pauh Duo Kecamatan Pauh Duo Kabupaten Solok Selatan. Data persepsi dan sikap masyarakat diperoleh melalui wawancara langsung dengan masyarakat, kemudian dijadikan dalam bentuk data kualitatif.

\section{a. Persepsi Masyarakat Tentang Perlindungan Hutan Di Nagari Kapau Alam Pauh Duo}

Berdasarkan hasil wawancara yang telah dilakukan dengan masyarakat Nagari Kapau Alam pauh Duo, maka terlihat bahwa persepsi masyarakat tentang perlindungan hutan masih menganggap hutan sebagai mata pencarian mereka, jadi apapun yang kita lakukan terhadap hutan tidak akan menimbulkan kerusakan hutan. Dapat kita lihat bahwa masyarakat yang berpendidikan rendah ( Tidak tamat
SD-SMA) berangggapan bahwa hutan itu sebagai mata pencaharian mereka, bagi mereka tanaman yang ada di hutan adalah hak mereka. Sebagian masyarakat yang berpendidikan tinggi (PNS) menganggap bahwa hutan itu harus di jaga dan dilestarikan keberadaannya.

\section{b. Sikap Masyarakat Tentang Perlindungan Hutan di Nagari Kapau Alam Pauh Duo}

Berdasarkan wawancara di dengan Masyarakat di Nagari Kapau Alam pauh Duo dapat di simpulkan bahwa Sikap negatif masyarakat tentang perlindungan hutan dapat kita lihat bahwa masyarakat yang berpendidikan rendah ( Tidak tamat SD- SMA) dan bermata pencaharian sebagai petani, perabot kayu/toke kayu masih mengambil kayu-kayu besar yang ada di hutan untuk 
memenuhi kebutuhan sehari-hari. Sebagian masyarakat yang yang berpendidikan tinggi ( PNS) masih juga melakukan penyimpangan secara tidak langsung terhadap hutan, hal ini dikarenakan mereka memerintahkan orang lain untuk menggarap/mengolah, dan mengambil hasil-hasil yang ada di areal perladangan nya.

Persepsi adalah sebagai suatu proses memperhatikan dan menyeleksi, mengorganisasikan dan menafsirkan stimulus lingkungan (Gitosudarmo, 2002) Dan sikap dikatakan sebagai suatu respon. Respon hanya akan timbul apa bila individu dihadapkan pada suatu stimulus yang menghendaki timbulnya reaksi individual, respon evaluatif berarti bentuk respon yang dinyatakan sebagai sikap yang didasari oleh proses evaluasi dari diri individu (Slameto, 2010)

Persepsi masyarakat tentang perlindungan hutan bahwa masyarakat masih menganggap hutan sebagai tempat mata pencarian mereka, di garap atau tidak pun hutan tidak akan menimbulkan permasalahan apapun, sedangkan sikap negatif masyarakat tentang perlindungan hutan dapat kita lihat bahwa masyarakat masih mengambil kayu di hutan salah satu nya menebang kayu-kayu besar yang ada di daerah hulu, kemudian membuka hutan untuk lahan perkebunan dan membakar hutan.

Penebangan kayu secara liar ini masih bisa terjadi disebabkan adanya penyelewengan surat perizinan oleh para toke atau agen kayu yang memiliki surat izin menebang kayu dengan kriteria kayu yang telah ditentukan. Penyelewengan terhadap surat izin bisa terjadi karena ada kerja sama antara agen kayu dengan oknum-oknum atau pejabat daerah Solok Selatan.

Jadi, mereka tidak takut dalam melakukan penyelewangan terhadap hutan di nagari Kapau Alam Pauh Duo, karena mereka ada yang melindungi atau dekingan. Agen kayu biasanya menjual kayu yang didapatkan ke luar daerah Solok Selatan dalam bentuk kayu gelondongan. Akibat dari penebangan hutan secara liar ini menimbulakan bencana alam berupa galodo (banjir bandang) dan tanah longsor. Temuantemuan penelitian selaras dengan fungsi hutan, salah satu fungsi hutan yaitu mengatur tata air, mencegah dan membatasi banjir, erosi, serta memelihara kesuburan tanah. Jadi berdasarkan temuan penulis dengan melakukan wawancara dengan Informan penelitian bahwa di Nagari Kapau Alam Pauh Duo benar terjadi kerusakan hutan yang mengakibatkan banjir bandang dan longsor, disebabkan kayu yang akarnya berfungsi sebagai pengatur tata air dan erosi tidak ada lagi sehingga menimbulkan banjir bandang dan longsor.

\section{Penutup}

\section{Kesimpulan}

Berdasarkan hasil penelitian yang dilakukan di lapangan, peneliti dapat menarik kesimpulan tentang Persepsi dan Sikap Masyarakat Tentang Perlindungan Hutan di Nagari Kapau Alam Pauh Duo, Kecamatan Pauh Duo, Kabupaten Solok Selatan dirinci sebagai berikut:

Persepsi masyarakat tentang perlindungan hutan dapat kita lihat 
bahwa masyarakat yang berpendidikan rendah (Tidak tamat SD-SMA) dan bermata pencaharian sebagai petani berangggapan bahwa hutan itu sebagai mata pencaharian mereka, bagi mereka tanaman yang ada di hutan adalah hak mereka. Sebagian masyarakat yang berpendidikan tinggi (PNS) menganggap bahwa hutan itu harus di jaga dan dilestarikan keberadaannya.

Sikap negatif masyarakat tentang perlindungan hutan dapat kita lihat bahwa masyarakat yang berpendidikan rendah (Tidak tamat SD- SMA) dan bermata pencaharian sebagai petani, perabot kayu/toke kayu masih mengambil kayu-kayu besar yang ada di hutan untuk memenuhi kebutuhan sehari-hari. Sebagian masyarakat yang yang berpendidikan tinggi ( PNS) masih juga melakukan penyimpangan secara tidak langsung terhadap hutan, hal ini dikarenakan mereka memerintahkan orang lain untuk menggarap/mengolah, dan mengambil hasil-hasil yang ada di areal perladangan nya.

\section{Saran}

Berdasarkan penelitian dan kesimpulan yang dikemukakan di atas maka peneliti menyarankan sebagai berikut:

Diharapkan kepada Pemerintah Daerah lebih ketat dalam melaksanakan Undang-Undang tentang penebangan Kayu-Kayu Besar supaya tidak ada lagi agen kayu yang masih berani mengambil kayu yang bestatus dilindungi di Nagari Kapau Alam Pauh Duo.

Kemudian diberikan juga penyuluhan kepada masyarakat, supaya mereka tahu mana kayu yang boleh ditebang. Supaya mereka mengetahui akibat dari penebangan kayu-kayu besar tersebut.

\section{Daftar Rujukan}

Ahmadi, Abu. 2007. Psikologi Sosial. Jakarta: Rineka Cipta

Gitosudarmo, dkk. 2002. Perilaku Keorganisasian. BPFE, Yogjakarta

Indriyanto. 2010. Ekologi Hutan. Jakarta : Bumi Aksara

Moleong, Lexy J.2006. Metodologi Penelitian Kualitatif. Bandung: PT.Remaja Rosdakarya

Nagel, P.Julius. 2011. Pelestarian Hutan dalam Hubungannya dengan Lingkungan dan Potensi Ekonomi : Jurnal

Slameto. 2010. Belajar dan Faktor-faktor yang Mempengaruhinya. Jakarta: Rineka Cipta

Supriyadi, Bambang Eko. 2013. Hukum Agraria Kehutanan ( Aspek Hukum Pertahanan dalam Pengelolaan Hutan Negara). Rajawali Press : Jakarta

Surwon, Wirawan sarlito. 1982. Pengantar Umum Pisikoligi. Jakarta : Bulan Bintang.

Undang-Undang Nomor 41 Tahun 1999 tentang Kehutanan

Undang-Undang Nomor 23 Tahun 1997 tentang Pengelolaan Lingungan Hidup

Walgito, Bimo. 2003. Pengantar Psikologi Umum. Yogyakarta : Andi 